\title{
Conjugated iminopyridine based Azo dye derivatives with efficient charge transfer for third order nonlinearities
}

\author{
A.P. Kerasidou ${ }^{a}$, F. Khammar ${ }^{\mathrm{a}, \mathrm{b}, \mathrm{c}}$, K. Iliopoulos ${ }^{\mathrm{a}, \mathrm{d}}$, A. Ayadi ${ }^{\mathrm{a}, \mathrm{e}}$, A. El-Ghayoury ${ }^{\mathrm{a}}$, N. Zouari ${ }^{\mathrm{e}}$, T. Mhiri ${ }^{\mathrm{e}}$, \\ B. Sahraoui ${ }^{\text {a,* }}$ \\ ${ }^{a}$ LUNAM Université, Université d'Angers, CNRS UMR 6200, Laboratoire MOLTECH-Anjou, 2 Bd Lavoisier, 49045 Angers Cedex, France \\ ${ }^{\mathrm{b}}$ Université Cherif Mesaadia, route d'Annaba B.P.1553, 41000 Souk-Ahras, Algeria \\ ${ }^{\mathrm{c}}$ Université Badji Mokhtar, 23000 Annaba, Algeria \\ ${ }^{\mathrm{d}}$ Institute of Chemical Engineering Sciences, Foundation for Research and Technology Hellas (FORTH/ICE-HT), 26504 Patras, Greece \\ e Laboratoire de physicochimie de l'Etat Solide, Département de Chimie, B.P. 1171, Sfax 3038, Sfax, Tunisia
}

\section{A R T I C L E I N F O}

Article history:

Received 8 February 2014

In final form 20 February 2014

Available online 28 February 2014

\begin{abstract}
A B S T R A C T
The third order nonlinearities of two azobenzene-iminopyridine molecular systems have been investigated employing the Z-scan technique at $532 \mathrm{~nm}, 30 \mathrm{ps}$. The objective of the work has been to study and to compare the nonlinearity of two iminopyridine based ligands substituted with one $\left(\mathbf{N O}_{2} \mathbf{A z o I m i n}\right.$ $\mathbf{o P y}, \mathbf{A})$ and two azobenzene units $\left(\left(\mathbf{N O}_{2} \mathbf{A z o}\right)_{2} \mathbf{I m i n o P y}, \mathbf{B}\right)$. The ligand $\mathbf{B}$ exhibits an extended conjugated structure and higher charge transfer within the molecule. Our results show high dependence of the nonlinearity on both the conjugation length within the molecule and on the number of the electron accepting units.
\end{abstract}

(c) 2014 Elsevier B.V. All rights reserved.

\section{Introduction}

Currently there is a growing demand for materials which can be utilized in photonic applications. The synthesis of novel organic materials with superior properties and a better insight on the relation between the molecular structure and the nonlinear optical (NLO) response is necessary. We have recently demonstrated a significant modification of the NLO response of dithiolene complexes by changing the counter cation [1]. We have also shown that the introduction of metal cations in a TTF-based ligand resulted in a switching of the nonlinear absorptive character from Reverse Saturable Absorption (R.S.A.) to Saturable Absorption (S.A.) [2]. Among organic materials, azobenzenes are well known to exhibit high second and third order nonlinearities [3-6], while one of the most widely investigated azobenzenes is the Disperse Red $1[7,8]$. Due to their very interesting properties, including the photoinduced trans-cis photoisomerization, azobenzene-based systems are promising candidates for numerous applications. It has been demonstrated for example that the cis-trans photo-isomerization and the high second order nonlinearity of the systems can be utilized in order to record data in thin azobenzene/polymer films $[9,10]$. In all cases it is of great importance to investigate the nonlinear optical response of these systems and to examine the relation be-

\footnotetext{
* Corresponding author. Fax: +33241735216.

E-mail address: bouchta.sahraoui@univ-angers.fr (B. Sahraoui).
}

tween their structure and the NLO efficiency. In this direction we report herein comparative third order nonlinear studies between two azobenzene-iminopyridine derivatives $\mathbf{A}$ and $\mathbf{B}$ (see Scheme 1). Note that compound (B) exhibits two electron accepting moieties $\mathrm{NO}_{2}$ and an extended conjugation in its molecular structure, which is expected to have an impact on the nonlinearity of the system.

\section{Experimental}

Our studies have been carried out by using Z-scan technique [11], employing a $30 \mathrm{ps}$ mode-locked $\mathrm{Nd}: \mathrm{YVO}_{4}$ laser with a repetition rate of $10 \mathrm{~Hz}$. Z-scan is a single beam technique for measuring both the nonlinear refraction and the nonlinear absorption. It consists of measuring the transmittance simultaneously in the far field by the so-called 'open aperture' (OA) and 'closed aperture' (CA) Zscans, as the sample is moving along the propagation path and through the focal plane of a focused laser beam. In particular, during OA measurements the totally transmitted light is collected by a large diameter lens and detected by a photomultiplier for each position of the sample, while for the CA a small part of the laser beam is collected after passing through an aperture $(\varnothing 1.3 \mathrm{~mm})$ placed in front of the photomultiplier. In order to account for the nonlinear absorption contribution in the CA signals, one can divide the CA recordings by the corresponding OA recordings. The curve obtained after this division is called 'divided' Z-scan and it contains information related only to the nonlinear refractive part of the 


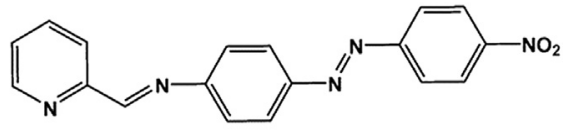

(a) $\mathrm{NO}_{2}$ AzoIminoPy, $\mathrm{A}$

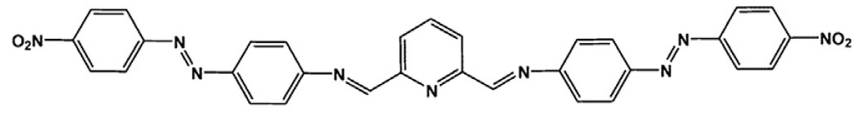

(b) $\left(\mathrm{NO}_{2} \mathrm{Azo}\right)_{2} \operatorname{Imino} \mathrm{Py}, \mathrm{B}$

Scheme 1. Chemical structures of the two studied systems $\mathbf{A}$ and $\mathbf{B}$.

nonlinearity. From the OA curves the nonlinear absorption can be determined. More specifically the OA Z-scan recordings can show a transmission maximum or a transmission minimum, corresponding to Saturable Absorption (S.A.) and Reverse Saturable Absorption (R.S.A.), respectively. On the other hand the 'divided' Z-scan can exhibit a 'valley-peak' or a 'peak-valley' configuration, corresponding to positive (self-focusing) or negative (self-defocusing) response.

The absorption and the refraction index of a material under intense laser excitation can be expressed, considering also the nonlinear terms, as:

$\alpha=\alpha_{0}+\beta I_{0}$

$n=n_{0}+\gamma^{\prime} I_{0}$

where $\alpha_{0}\left(\mathrm{~cm}^{-1}\right)$ and $\mathrm{n}_{0}$ are the linear absorption and refraction parameters, $\beta(\mathrm{cm} / \mathrm{W})$ is the nonlinear absorption coefficient, $\gamma^{\prime}\left(\mathrm{cm}^{2} / \mathrm{W}\right)$ is the nonlinear refraction parameter and $I_{0}\left(\mathrm{~W} / \mathrm{cm}^{2}\right)$ is the on-axis intensity of the laser beam.

From the CA, OA curves the nonlinear refraction parameter $\left(\gamma^{\prime}\right)$ and the nonlinear absorption coefficient $(\beta)$ can be determined using the following equations:

$T=\sum_{m=0}^{\infty} \frac{\left[-\beta I_{0} L_{\text {eff }} /\left(1+z^{2} / z_{0}^{2}\right)\right]^{m}}{(m+1)^{3 / 2}}$

$T=1-\frac{4 \Delta \Phi_{0} x}{\left(x^{2}+9\right)\left(x^{2}+1\right)}$

where $T$ is the normalized transmittance, $L_{\mathrm{eff}}$ is the effective thickness of the sample, $\alpha_{0}$ is the linear absorption coefficient at the laser excitation wavelength and $\Delta \Phi_{0}$ is the on-axis nonlinear phase shift at the focus and its related with the nonlinear refraction parameter through the equation $\Delta \Phi_{0}=k I_{0} \gamma^{\prime} L_{\text {eff }}$.

The nonlinear absorption and refraction parameters are related to the third order nonlinear susceptibility by the following equations:

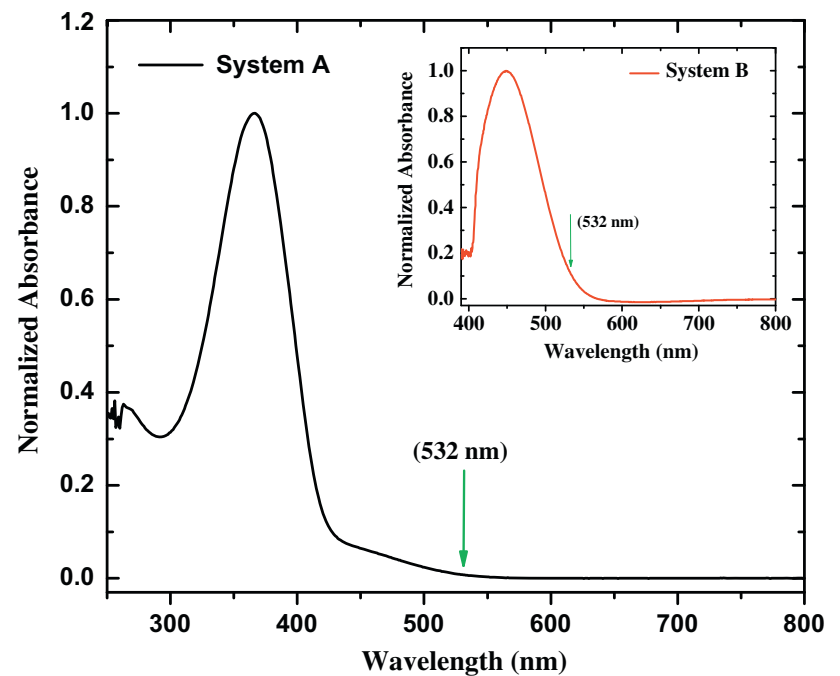

Figure 1. UV-Vis absorption spectra of compound $\mathbf{A}$ dissolved in toluene. Inset: UV-Vis absorption spectra of compound $\mathbf{B}$ dissolved in nitrobenzene.

$$
\begin{aligned}
& \operatorname{Im} \chi^{(3)}(e s u)=\frac{10^{-7} c^{2} n_{0}^{2}}{96 \pi^{2} \omega} \beta\left(\mathrm{cm} W^{-1}\right) \\
& \operatorname{Re} \chi^{(3)}(e s u)=\frac{10^{-6} c n_{0}^{2}}{480 \pi^{2}} \gamma^{\prime}\left(\mathrm{cm}^{2} W^{-1}\right)
\end{aligned}
$$

where $c$ is the speed of light in $\mathrm{cm} / \mathrm{s}$ and $\omega$ is the fundamental frequency given in cycles $\mathrm{s}^{-1}$.

The second order hyperpolarizability $(\gamma)$ can be deduced from the third order nonlinear susceptibility $\left(\chi^{(3)}\right)$ using the equation:

$\gamma=\frac{\chi^{(3)}}{N L^{4}}$

where $N$ is the number of molecules per volume and $L$ is the local field correction factor.

\section{Results and discussion}

The chemical structures of the studied azobenzene-imino pyridine based dreivatives, namely $\mathbf{N O}_{2} \mathbf{A z o}_{2}$ IminoPy (A) and $\left(\mathbf{N O}_{2} \mathbf{A z o}\right)_{2}$ IminoPy $(\mathbf{B})$ are presented in Scheme $1(\mathrm{a}$ and $\mathrm{b})$. Both molecules contain an electron accepting group $\left(-\mathrm{NO}_{2}\right)$, which is expected to enhance the charge transfer within the molecule and sequentially the nonlinear optical response.

The electronic absorption spectra of the two compounds were obtained using a UV-Vis spectrometer (Perking Elmer, model Lambda 19) in the spectral range of $250-800 \mathrm{~nm}$.

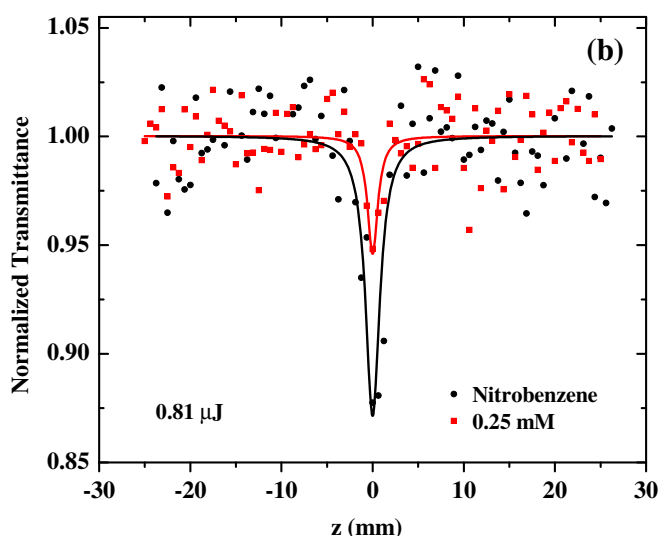

Figure 2. Characteristic 'open-aperture' Z-scan recordings of (a) System A and (b) System B and the corresponding solvent (nitrobenzene). 

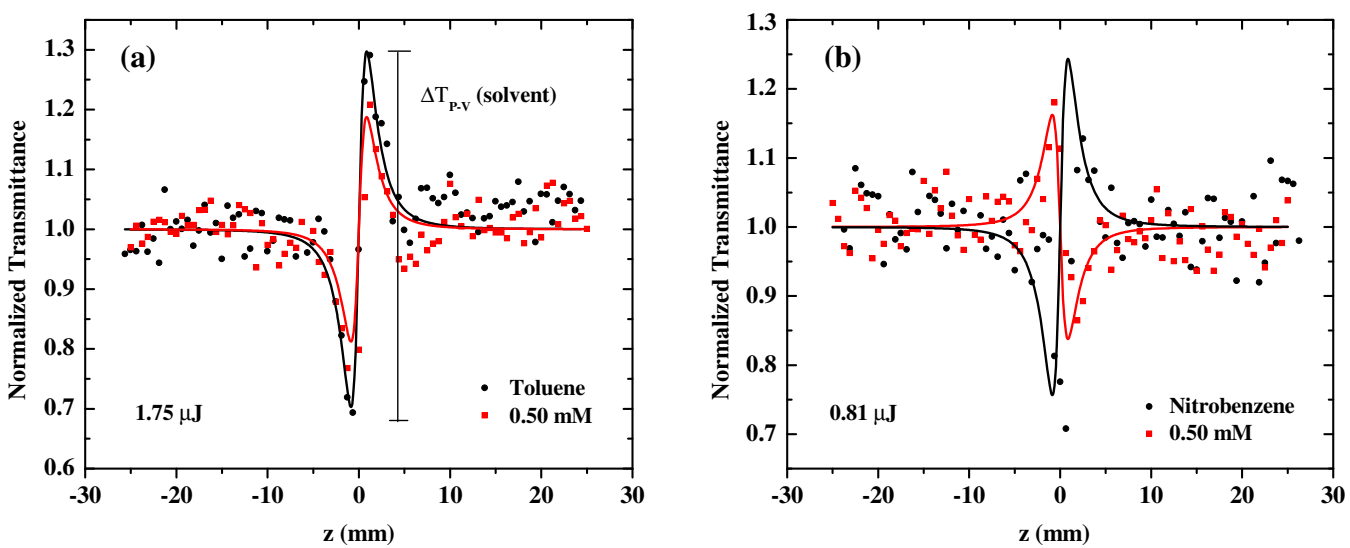

Figure 3. Characteristic 'divided' Z-scan recordings of (a) System A and toluene and (b) System B and nitrobenzene.

Table 1

Nonlinear optical parameters of the Azo based Iminopyridine A determined by means of the Z-scan technique (532 nm, $30 \mathrm{ps).}$

\begin{tabular}{|c|c|c|c|c|c|c|}
\hline & $\begin{array}{l}\mathrm{C} \\
(\mathrm{mM})\end{array}$ & $\begin{array}{l}\operatorname{Re} \chi^{(3)} \\
\left(\times 10^{-13} \text { esu }\right)\end{array}$ & $\begin{array}{l}\operatorname{Im} \chi^{(3)} \\
\left(\times 10^{-13} \mathrm{esu}\right)\end{array}$ & $\begin{array}{l}\operatorname{Re} \gamma \\
\left(\times 10^{-30} \text { esu }\right)\end{array}$ & $\begin{array}{l}\operatorname{Im} \gamma \\
\left(\times 10^{-30} \mathrm{esu}\right)\end{array}$ & $\begin{array}{l}\gamma \\
\left(\times 10^{-30} \text { esu }\right)\end{array}$ \\
\hline Compound A & $\begin{array}{l}2.50 \\
2.00 \\
1.75 \\
1.50 \\
1.00 \\
0.50\end{array}$ & $\begin{array}{r}-1.31 \pm 0.09 \\
-1.09 \pm 0.08 \\
-0.94 \pm 0.09 \\
-0.5 \pm 0.09 \\
-0.66 \pm 0.09 \\
-0.48 \pm 0.10\end{array}$ & $\begin{array}{l}0.64 \pm 0.09 \\
0.50 \pm 0.09 \\
0.45 \pm 0.08 \\
0.41 \pm 0.09 \\
0.28 \pm 0.06 \\
0.16 \pm 0.07\end{array}$ & $-0.03 \pm 0.01$ & $0.010 \pm 0.003$ & $0.03 \pm 0.01$ \\
\hline
\end{tabular}

Table 2

Nonlinear optical parameters of the Azo based Iminopyridine B determined by means of the Z-scan technique ( $532 \mathrm{~nm}$, $30 \mathrm{ps).}$

\begin{tabular}{|c|c|c|c|c|c|c|}
\hline & $\begin{array}{l}\mathrm{C} \\
(\mathrm{mM})\end{array}$ & $\begin{array}{l}\operatorname{Re} \chi^{(3)} \\
\left(\times 10^{-12} \text { esu }\right)\end{array}$ & $\begin{array}{l}\operatorname{Im} \chi^{(3)} \\
\left(\times 10^{-12} \text { esu }\right)\end{array}$ & $\begin{array}{l}\operatorname{Re} \gamma \\
\left(\times 10^{-30} \text { esu }\right)\end{array}$ & $\begin{array}{l}\operatorname{Im} \gamma \\
\left(\times 10^{-30} \text { esu }\right)\end{array}$ & $\begin{array}{l}\gamma \\
\left(\times 10^{-30} \text { esu }\right)\end{array}$ \\
\hline \multirow[t]{4}{*}{ Compound $\mathbf{B}$} & 1.00 & $-1.29 \pm 0.07$ & $\mathrm{n} / \mathrm{a}$ & \multirow[t]{4}{*}{$-0.37 \pm 0.2$} & \multirow[t]{4}{*}{$-0.20 \pm 0.02$} & \multirow[t]{4}{*}{$0.4 \pm 0.2$} \\
\hline & 0.75 & $-0.92 \pm 0.03$ & $\mathrm{n} / \mathrm{a}$ & & & \\
\hline & 0.50 & $-0.66 \pm 0.03$ & $-0.31 \pm 0.01$ & & & \\
\hline & 0.25 & $-0.08 \pm 0.02$ & $-0.13 \pm 0.01$ & & & \\
\hline
\end{tabular}
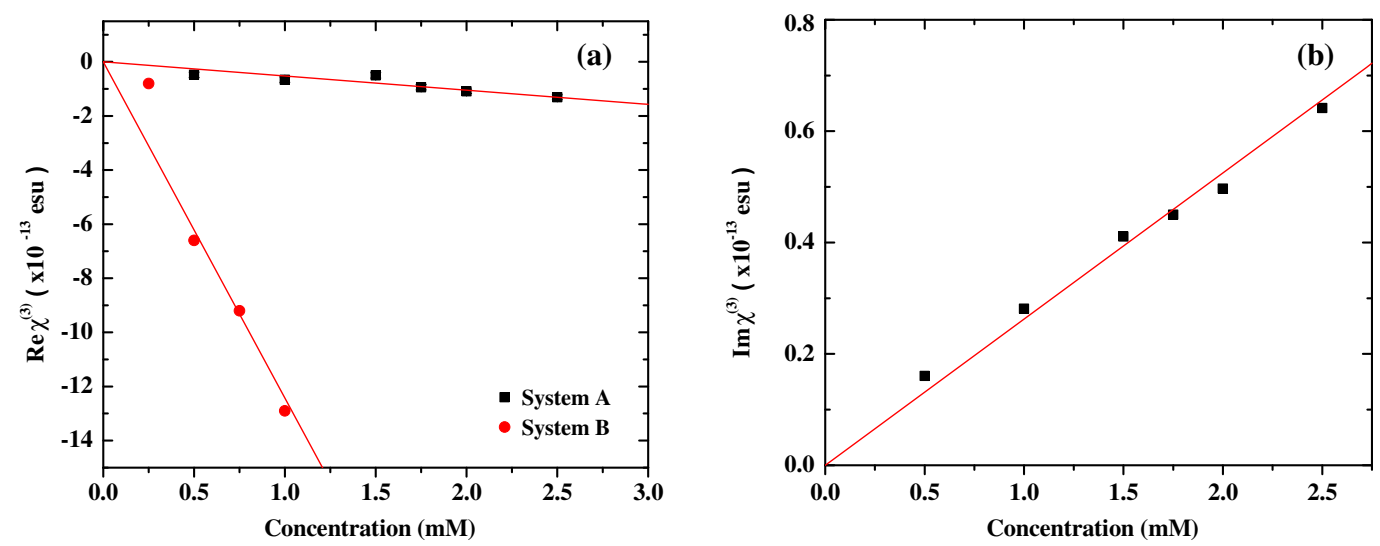

Figure 4. (a) $\operatorname{Re} \chi^{(3)}$ as a function of concentration for $\mathbf{A}$ and $\mathbf{B}$, (b) $\operatorname{Im} \chi^{(3)}$ as a function of concentration for compound $\mathbf{A}$.

The electronic absorption spectra for compound $\mathbf{A}$ recorded in toluene solution is presented in Figure 1 and is exhibiting a typical azobenzene absorption band located at $\lambda_{\max }=380 \mathrm{~nm}$. The electronic absorption spectra for compound $\mathbf{B}$ was recorded in nitrobenzene solution (inset Figure 1). This system exhibits a strong electronic absorption band that is red shifted towards the visible region of the spectrum, $\lambda_{\max }=455 \mathrm{~nm}$. This shift is mainly due to the use of nitrobenzene as solvent because the absorption peak of compound $\mathbf{B}$ recorded in toluene solution was also located at around $380 \mathrm{~nm}$ like in system $\mathbf{A}$.

In order to determine the nonlinear optical properties for compounds $\mathbf{A}$ and $\mathbf{B}$, different concentrations have been prepared for each compound. For solubility reasons compound $\mathbf{A}$ was dissolved in toluene and compound $\mathbf{B}$ in nitrobenzene. For the needs of the measurements the samples were put into $1 \mathrm{~mm}$ thick quartz cuvettes. In both cases the contribution of the solvents to the 
nonlinearity has been separately investigated. The measurements have been carried out at the frequency doubled laser beam $(532 \mathrm{~nm})$ and energy dependent measurements have been carried out for every concentration of each molecular system.

In Figure 2a and b characteristic 'open-aperture' Z-scan recordings are presented for systems $\mathbf{A}$ and $\mathbf{B}$ respectively. The contribution of nitrobenzene is shown in graph $2 \mathrm{~b}$ and was obtained under the same experimental conditions with those of system $\mathbf{B}$. On the contrary the nonlinear absorption of toluene has been found to be negligible compared with that of system $\mathbf{A}$. As it is obvious from Figure $2 \mathrm{a}$ and $\mathbf{b}$ the solutions of systems $\mathbf{A}$ and $\mathbf{B}$ exhibit a transmittance minimum around the focal point. As far as it concerns the solutions of system $\mathbf{A}$ the totality of the nonlinear absorption is attributed to the compound $\mathbf{A}$ (as the solvent has a negligible effect) so as a result the nonlinear absorption of system $\mathbf{A}$ is of Reverse Saturable Absorptive (RSA) character. On the contrary in the case of compound $\mathbf{B}$ the dip obtained in the case of the solutions is smaller than that of the solvent (nitrobenzene). As a result it can be deduced that the sign of the nonlinear absorption of compound $\mathbf{B}$ is opposite to that of the solvent corresponding to Saturable Absorption (SA) behavior. The fact that the absorption character of systems $\mathbf{B}$ changed comparing to system $\mathbf{A}$ is related to the fact that the increase of the conjugation length as well as the introduction of a second electron accepting nitro group modifies the energy levels of this system. So, for system B the SA can be attributed to the fact that the exited-state absorption cross-section is lower compared with that of the ground state, while the opposite applies for system $\mathbf{A}$. The reversing of the absorption character as reported elsewhere [12] can also depend for each molecule on the wavelength and on the intensity of the laser used.

Concerning the nonlinear refraction the response of the compounds has been studied comparatively with that of the solvents as they are well known to exhibit high nonlinear refractive parameters $[13,14]$. In Figure $3 a$ and $b$ characteristic 'divided' Z-scan recordings are presented for both systems together with the curves corresponding to the solvents. It can be seen that in the case of system $\mathbf{A}(0.5 \mathrm{mM}$ in toluene) a valley-peak configuration has been found, which has been however lower than that of the solvent. This leads to the result that the nonlinear optical refraction of compound $\mathbf{A}$ is negative (self-defocusing). A self-defocusing character (negative $\gamma^{\prime}$ ) has been also found in the case of compound B. The peak-valley configuration found in this case (Figure $3 \mathrm{~b}$ ) for the same concentration demonstrates a higher nonlinear refractive response for this system. In this sense the nonlinear refraction emanating from the dissolved compound surpasses that of the solvent resulting in a peak-valley configuration.

From the analysis of the 'open-aperture' and 'divided' Z-scan data, the nonlinear absorption coefficient $(\beta)$ and the nonlinear refractive parameter $\left(\gamma^{\prime}\right)$ have been determined using Eqs. (2) and (3). Then by means of Eq. (4) the real and the imaginary part of $\chi^{(3)}$ for each concentration have been deduced and are shown in Tables 1 and 2 for the compounds $\mathbf{A}$, B respectively.

Moreover in Figure $4 \mathrm{a}$ and $\mathrm{b}$ the concentration dependence of the real and imaginary parts of $\chi^{(3)}$ for both systems is shown. As it is expected a linear dependence upon the concentration is observed verifying that no saturation of the response for this range of concentrations/energies was taking place. Additionally it is obvious that the magnitude of the slope of the fit in the case of the nonlinear refraction of compound $\mathbf{B}$ is much higher than that in the case of compound $\mathbf{A}$. The slopes of these fittings are directly related with the real part of the second order hyperpolarizabilities (Eq. (5)), which have been derived and can be seen also in Tables 1 and 2 for the two molecular systems. As expected from graph $4 a$ the $\operatorname{Re} \gamma$ of $\mathbf{B}$ is dramatically enhanced with respect to that of $\mathbf{A}$ (about one order of magnitude). Concerning the $\operatorname{Im} \chi^{(3)}$, concentration dependent measurements have been achieved only in the case of system $\mathbf{A}$. In the case of system $\mathbf{B}$ higher nonlinear absorption has been found which resulted to cancellation of the contribution of the solvent for high concentrations. As a result in the case of higher concentrations (more than $0.5 \mathrm{mM}$ ) and under the present experimental conditions low signal to noise ratios have been found. Consequently the imaginary part of the second order hyperpolarizability has been determined from the lower concentrations as it can be seen in Table 2 .

In summary we report that the increase of the nonlinear optical response for compound $\mathbf{B}$ comparing to that of compound $\mathbf{A}$ can be attributed to the increase of the conjugation length of the molecule. This finding is in good agreement with results reported by Y. Qian et. al. [15] who have shown that larger hyperpolarizabilities can be obtained in azobenzene-based systems by increasing the molecular conjugation length and the donor-acceptor conjugation path.

\section{Conclusions}

In summary, two novel $\pi$-conjugated azo based iminopyridine derivatives were studied using the Z-scan technique at $532 \mathrm{~nm}$ employing a $30 \mathrm{ps}$ mode-locked $\mathrm{Nd}: \mathrm{YVO}_{4}$ laser with a repetition rate of $10 \mathrm{~Hz}$. Compound $\mathbf{A}$ exhibited RSA process and self-defocusing while compound B exhibited SA and self-defocusing. The Zscan measurements also revealed the increase of the nonlinearities for these iminopyridine based systems with the increase of the conjugation length of the molecule. The second order hyperpolarizability values were obtained to be $-0.03 \times 10^{-30}$ esu and $0.40 \times 10^{-30}$ esu for compound $\mathbf{A}$ and $\mathbf{B}$, respectively. These findings are highly desirable in nonlinear optics since the combination of SA and RSA as well as the tuning of the NLO response, upon conjugation length or the number of acceptor units, can be used for several photonic applications.

\section{Acknowledgements}

K. I. acknowledges the support from the European Commission and the General Secretariat for Research and Technology (Greece) for a National Strategic Reference Framework (NSRF) Project (PE3-(1612)).

\section{References}

[1] K. Iliopoulos, A. El-Ghayoury, B. Derkowska, A. Ranganathan, P. Batail, D. Gindre, B. Sahraoui, Appl. Phys. Lett. 101 (2012) 261105.

[2] K. Iliopoulos et al., Opt. Express 20 (2012) 25311.

[3] I. Papagiannouli et al., Chem. Phys. Lett. 554 (2012) 107.

[4] H. El Ouazzani, K. Iliopoulos, M. Pranaitis, O. Krupka, V. Smokal, A. Kolendo, B. Sahraoui, J. Phys. Chem. B 115 (2011) 1944.

[5] F. Dong, E. Koudoumas, S. Couris, Y. Shen, L. Qiu, X. Fu, J. Appl. Phys. 81 (1997) 7073.

[6] N. Liaros, S. Couris, L. Maggini, F. De Leo, F. Cattaruzza, C. Aurisicchio, D. Bonifazi, ChemPhysChem 14 (2013) 2961.

[7] V. Rodriguez, F. Adamietz, L. Sanguinet, T. Buffeteau, C. Sourisseau, J. Phys. Chem. B 107 (2003) 9736.

[8] M.A. Mortazavi, A. Knoesen, S.T. Kowel, B.G. Higgins, A. Dienes, J. Opt. Soc. Am. B 6 (1989) 733 .

[9] D. Gindre et al., J. Opt. Soc. Am. B 24 (2007) 532.

[10] D. Gindre, A. Boeglin, A. Fort, L. Mager, K.D. Dorkenoo, Opt. Express 14 (2006) 9896.

[11] M. Sheik-Bahae, A.A. Said, T.-H. Wei, D.J. Hagan, E.W. Van Stryland, IEEE J. Quantum Electron. 26 (1990) 760.

[12] J. Wang, B. Gu, H.-T. Wang, X.-W. Ni, Opt. Commun. 283 (2010) 3525

[13] S. Couris, M. Renard, O. Faucher, B. Lavorel, R. Chaux, E. Koudoumas, X. Michaut, Chem. Phys. Lett. 369 (2003) 318.

[14] P.P. Ho, R.R. Alfano, Phys. Rev. A 20 (1979) 2170.

[15] Y. Qian, G. Xiao, G. Wang, B. Lin, Y. Cui, Y. Sun, Dyes Pigments 75 (2007) 218. 